\title{
19. ONLINE SELF-HELP FOR YOUNG DANES
}

\begin{abstract}
To support young people in Denmark who are making decisions about their future education the national Education Guide portal (Uddannelseguiden UG.dk) offers tools for information and career exploration along with the online eGuidance (eVejledning). The general purpose of the online tools is to extend career learning activities beyond the activities facilitated by a career counsellor. Focusing on the self-help tools 'Min Gymnasievej' (My way to Upper secondary) and 'Mine styrker' (My Strengths) this article describes the challenges of the digital transformation of analogue career guidance tools and of their usage by the counsellees.
\end{abstract}

\section{INTRODUCTION}

The Nordic countries are often positioned as digital frontrunners in both a European and a global context (e.g. Alm et al., 2016; European Commission, 2017a). Denmark is among the world leaders in digitalisation. The new governmental digital plan known as The Digital Strategy 2016-2020 (Agency for Digitalisation, n.d.) - aims to further enhance close public sector collaboration to deliver good, efficient and coherent services to the public and businesses (European Commission, 2017b). Denmark has one of the highest levels of internet access in Europe (Eurostat, 2018). Over $90 \%$ of the population between the ages of 16 and 89 have internet access in their home, and four out of five access the internet on a smart phone (Danmarks Statistik, 2017). The Public Digitalisation Strategy has addressed the Danish citizens as digital citizens since 2001. The political vision is, that the digital citizen can act autonomously in the digital administration (Andersen, 2008). By the digitisation of all communication with the public sector, partly through an extensive and mandatory digital self-service, Danes' use of ICT has been further encouraged. According to the latest statistics $88 \%$ now use the public digital self-services (Danmarks Statistik, 2017).

Among young Danes who have grown up with digital media, digital accessibility to public institutions is expected and taken for granted. Contact with public services is seen as one of many interactions with online services in general (Andersen, 2008). Computers and phones, bringing the online and off-line environment together, are natural components of young Danes' everyday lives. Other generations do not have the same familiarity, and the use of these media has to be learned (Hansen, 
2013). This is also true of most Danish guidance counsellors. While the internet has gone from searching for knowledge in web 1.0, to a means of interactive communication in web 2.0, to a means of communal construction of knowledge in web 3.0 (Law, 2010), the use of digital media in Danish counselling has generally been limited by the counsellor's own attitude to and familiarity with them, and on the structural framework for counselling services (Kettunen, Vuorinen, \& Sampson, 2015).

To support young people in Denmark to prepare to make decisions about their future education the national Education guide portal, abbreviation UG (Uddannelseguiden UG.dk in Danish) along with eGuidance service (eVejledning) (eGuidance) has been established. In the early stages UG was a 'quiet' library with information on education and job opportunities. Today UG and eVejledning offer digitally supported and digitally based guidance including interactive self-help tools. The digitally based guidance can take place via chat, telephone, e-mail, social media as well as webinars, and is supported through online information articles and various tools. UG and eVejledning cannot offer face to face counselling and so the focus has been on testing the counselling potential of digital media and developing self-help tools. UG and eVejledning use the affordances of online technologies to deliver on policy aims to support young people and adults' access to career information and support to aid them in educational and career development.

\section{THE EDUCATION GUIDE (UG.DK)}

To make it easier for Danes to find and choose between educational programmes and career opportunities the Ministry of Education decided on a major guidance reform in 2003 (Jensen, Chapter 8, this volume). Career guidance was brought together into a system independent of educational institutions, the main objective being to provide guidance at primary and at secondary schools (Jensen, Chapter 8 , this volume). Professionalising counsellors by unifying their education as a single national diploma or master programme was also part of the reform. To enhance access to career information according to EU's Memorandum on life-long learning (European commission, 2000) and on life-long career guidance, the portal UG was established with the reform as well.

In 2011 the ministry established the national guidance centre eVejledning as an integrated part of the portal. Thus UG contains comparable information on public education and employment and articles on the current labour market as well as links to eVejledning, educational institutions and other relevant organisations. Another part of the portal is the Knowledge Centre for Career Guidance (VidenCenter for Vejledning in Danish) for professional career guidance counsellors which provides articles, literature and information about courses and conferences for counsellors. Most of UG's content is text-based, but there are also multimedia elements such as films, graphics and interactive inspirational tools. UG has been developed into 
a flexible web site that adapts to desktop, tablet and smart phone with the visual adjustments that these media demand, thus ensuring optimal usability and availability. To quality assure information on UG, a corps of external UG-ambassadors recruited from Danish career counsellors provide feedback to the editors and developers of the portal on points for improvement.

It is part of the ministry's expectations that many young people will use their own initiative to seek information and use the tools on the portal. The introduction to the portal given by counsellors and teachers to their pupils has to take this into account. In national level UG is regarded as a core of career guidance in Denmark, and so, students are introduced to it through the school subject Education and Job and through counselling activities in schools. This is one of the reasons why the portal includes a tool-box for counsellors with videos and texts to help them introduce and make use of UG. eVejledning also arranges webinars for counsellors on UG's structure and potential.

The front page of the UG portal presents various entrances you can choose between. The entrances represent the different educational levels: 'Youth education', 'Further education' and 'Adult and supplementary education' as well as 'Information on jobs and the labour market'. Under the heading 'Get inspiration' there is an overview of the tools categorised by the target groups from the front page (see Figure 19.1).

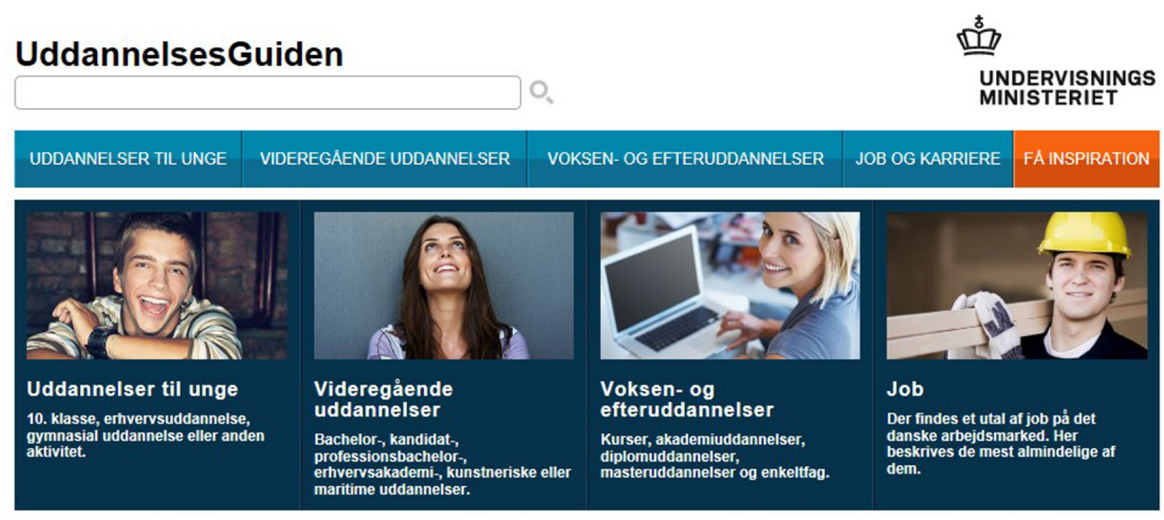

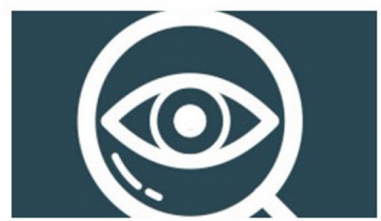

Uddannelseszoom er opdateret Sammenlign info om bl.a. uddannelsers studiemiljø, kvalitet og relevans.

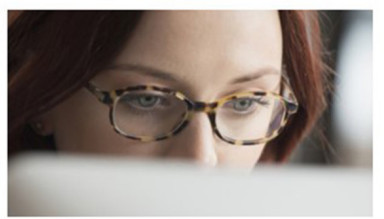

Kvote 1-fristen nærmer sig

Ansøgningsfrist til de videregảende uddannelser er 5. juli Kl. 12. Læs, hvordan du søger.

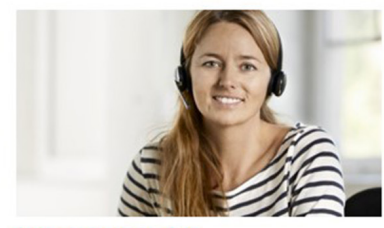

Spørg en vejleder

eVejledning vejleder om uddannelsesvalg via chat, mail og telefon

Figure 19.1. The front page of Uddannelsesguiden (UG) 
Alongside the entrances to the different education levels a menu provides users with a way of navigating around the site. The middle section of the page emphases content that addresses the guidance needs at the current stage in the school year, such as articles on the admission rules to youth education and higher education. This part gives the front page a dynamic and varied appearance with topical headings and photos. At the bottom of the page there is a 'footer' with links to selected areas of the portal.

\section{Active Participation in the Guidance Process through Online Activities}

The UG articles provide information on career possibilities to help young people discover future paths. The digital tools help young people to organise information and focus on their own individual possibilities and priorities. The portal also provides direct access to eVejledning so that young people can access personal guidance to gain a better understanding of their preferences. Personal guidance and tools for selfguidance are aimed at facilitating the counsellee's self-reflection. This is an essential premise for the self-knowledge that is necessary to have a personal sounding board for the many future possibilities. They can be used according to wherever the counsellee is in her career learning process.

A decisive factor, determining whether pupils find the resources available on UG, is the introduction to the portal given at their own school in the subject Education and Job, and in the collective guidance given class-wise by the school counsellors. Informal guidance via their social network and random searches on the internet can, via the portal, be supplemented with online activities that draw on the constructive offline experiences of career practitioners. Use of the tools can help the counsellee to be a more active participant in his/her own clarification and guidance process. For example, the fact that the tool's response is dependent on the counsellee's input allows multiple attempts with varying premises, and this gives a good starting point for seeing oneself in different scenarios. Using the tools in this way can give rise to surprise at the results, and thus to renewed consideration of one's own potential. The clarification reached with the help of the formalised self-help tools can be worked on in the formal guidance situation in schools or eVejledning. The active inclusion of digital resources before, during and after formal guidance sessions, individual and collective, can be important for the young person's career learning process, and her ability to find answers independently. In a knowledge society like Denmark, where education is seen as a path to personal and social progress, formalised self-help via digital tools is not only a possibility but a condition for counsellor and counsellee with an ever-increasing demand for technological solutions from counsellees and from politicians.

\section{THE DEVELOPMENT OF SELF-HELP TOOLS}

In Denmark self-help via digital tools is one of the components of career counselling activities in secondary school. The self-help approach adopted in the country draws 
on Cognitive Information Processing theory (Sampson, Lents, Reardon, \& Peterson, 2003). In accordance with the theory our self-help tools are meant for independent or brief counsellor-assisted use for individuals with a high degree of career readiness. Self-help falls midway between professional career guidance and the informal guidance that one receives from friends, family, the media and society. Professionally developed self-help tools can be accessed through UG by young people for free and on their own initiative, or at the instigation of a career guidance counsellor. In this way these counselling activities are aligned with the learning-oriented approach found in Danish career guidance (see Skovhus \& Thomsen in this volume).

The development and realisation of the digital self-help tools in UG takes place in close co-operation between counsellors, editors, developers, technicians and web usability experts. A major factor in qualifying the work process is the use of co-creation, where the target group for the tool is actively involved in the process from an early stage. The democratic nature of the development process, in which end users or stakeholders are involved in developing the digital tools or services they themselves will be using, has long traditions in Scandinavia (Kettunen \& Felt, Chapter 20, this volume). The interdisciplinary group validates the developed tools from two perspectives, firstly focusing on its quality as a guidance tool and secondly on its usability (Hansen, 2012). The production of ideas and tests of prototypes are typically iterative processes, taking place over a concentrated period of a few days, inspired by the Sprint method developed by Google Venture (Knapp, Zeratsky, \& Kowitz, 2016). Sprint is an effective way of testing the guidance potential and the usability of the relevant tool before it is finalised. The starting point for the development is the content of the tool. A single tool on UG cannot in itself relate to all the various phases of the career learning process, but it does have to address typical questions and problems for the phase in question. The first step for developing the content is to clarify the tool's purpose and target group by using such questions as: What is the tool supposed to do? Who is the tool intended for? The answers to these basic questions construct the tool's didactic structure and guide the technical implementation of the content. Generally, the self-help tools on UG are intended to produce 'turbulence' and by doing so give rise to reflection and reconsideration, so that the counsellee can see oneself and one's educational potential from different viewpoints. These tools are meant to be door openers, not a list of answers.

The humanist non-directive approach to career guidance, which typifies Danish counselling (Plant, 2009), is also the basis for the digital tools on UG. Danish counselling has been strongly inspired by Carl Roger's person-centred theory (Rogers, 1951), which since the nineties has been supplemented by constructivist approaches (Plant, 2006). Over the past few years Bill Law's theory on careers education and guidance, which offers a clear pedagogic framework for developing career learning (Law, 2001) has gained a foothold in Danish career guidance and counselling, and thus also in the development of the tools on UG. The framework 
emphasises the essential career competences (DOTS) enabling a contemporary career choice: Decision learning (D), Opportunity awareness (O), Transition learning (T), and Self-awareness (S). And it describes four progressively established levels of career learning (New DOTS), which Law describes as sensing, sifting, focusing and understanding.

In developing the self-help tool, the central question, didactically, is: In what way should the counsellee benefit from using the tool? In developing the tool the counsellee is perceived in the centre as an active agent, giving input and receiving response from the tool. The self-help tool activity serves to induce learning on one or several career learning levels. These could, for example, be learning concepts or working with oneself on the basis of investigative questions, dilemmas and so on. The response could be formed as a list of all input as reference for further personal work, or as an overview of educational possibilities sorted by various criteria - these being chosen as relevant by the counsellee. Didactically the portals tools can be classified as scaffolding teaching aids (Hansen \& Bundgaard, 2013) that support the counsellee's reflection process regarding life and career. In other words, the designed framework must be such that it supports a structured dialogue between the counsellee and the tool, with focus on choice and reasons during the activity. An important element in the development process is that the design team observe analogue learning processes to gain practical insights into the learning process that the tool is intended to support. When previously tested analogue learning aids are to be converted to digital media, this phase can be omitted.

This didactic design is accompanied by user-friendly interface design to ensure accessibility. As an aid to the counsellee's completion of the activities, texts are written in a clear and straightforward language, and activities components are arranged in an order that conforms to the logic of both content and design. Clear instructions are the path to self-help.

Visually the idea is for the site to have as few elements (buttons, boxes, icons, pictures) as possible, in a coordinated colour scheme, to give a simple and accessible navigation structure. From a multitude of tests we know that the counsellees mostly skim through the screen text. Headings and sub-headings strategically placed can support this navigation strategy, just as it is an advantage for the reader's concentration that the text is divided into manageable bites. At an early stage in the process a prototype of the tool is tested in educational settings by the whole group, each with her own take on the pupils' interaction with the tool. The focus on this phase is on usability and whether the technical solutions work. The main questions are: Is the tool useful for guidance counselling? Are the technical solutions user-friendly? The test could be a systematic 'walk-through' of all functions, where various disciplines note whether pupils can find what they are looking for, and how they find it. Pupil reactions during the test are also noted for use in the subsequent adjustment. The test can also be a 'think-out-loud' test, where pupils make running comments while testing the activity. 
The guidance counselling intention of the tool can be put under pressure in this meeting with the target group. The most common feedback from pupils is that they want quick and easy operation with clickable choices rather than text answers. Many of the UG tools are designed with both options in order to keep pupils motivated to stay. It is also perceived that pupils want an immediate response with a tangible result from using a tool, but that the result should preferably keep all future paths open and not shut off any possibilities. This reaction is not surprising, since Danish research into contemporary young people shows that they prefer to avoid specific and long-term plans, which may well turn out to be impracticable anyway in a changing world (Hansen, 2015). Results from these designed digital activities are not definitive, as the activities can be repeated as many times as desired. Thus, several UG tools contribute to a reduction of complexity and present the pupil with relevant possibilities within a limited area of interest enabling one to organise and gain oversight over the information on education and employment.

Didactics and user-friendliness go hand in hand in developing self-help tools. Their usability for the young pupils should however be seen in combination with especially guidance activities with a counsellor, and with the school subject Education and Job.

\section{FROM ANALOGUE CAREER GUIDANCE IDEA TO DIGITAL TOOL}

With digital learning technologies it is possible to rethink the form and didactic content of guidance activities, not only as an enhancement of the learning process but also as a transformation of it (Reimer-Mattesen, 2012). A combination of an analogue guidance session with digital activities can benefit pupils' learning, and a practical demonstration of the tool can induce them to use the tool themselves, perhaps with their parent. Involving digital media in guidance activities is not a benefit in itself but can be made beneficial by its planned use.

UG has a section called "My UG" (Mit UG in Danish). The My UG universe contains five digital guidance tools for secondary school pupils. They can be incorporated in guidance activities, preferably led by a practitioner, or in classwork in Education and Job. The tools in My UG are not intended as part of a radical transformation of the learning process, but offer the pupil extended participation compared to analogue tools, so the digital media support the idea of career learning with active participation in focus. With a wide range of multimedia elements such as posters, videos, sounds and photos, and websites with the pupils as active participants and contributors, the combined effect of technology can induce a considerable change of the career learning process.

Two of the tools on "My UG", My Way to Upper secondary (Min Gymnasievej in Danis) and My Strengths (Mine Styrker in Dahish), have both been developed from a well-tried analogue guidance tool. These tools can be used in the 'Sensing' stage of career learning, with focus on broadening horizons and increasing self-knowledge. They represent, too, the two poles that the portal's guidance resources operate between, namely simple matching and open reflection. My Way to Upper secondary 
accommodates the young people's wish for a tool that can, on a practical level, match the subjects they are interested in with the various forms of higher secondary schools. You could say that the tool has been developed from, or at least parallel with, trait theory, which is atypical in a Danish context. The idea came from a pupil who, together with a guidance counsellor, developed the board game "Valgstjernen" (The Star of Choice) to help pupils who were in doubt as to their choice of upper secondary schools. In the digital version the pupil chooses five subjects from an exhaustive list of all subjects at this level, regardless of which types of school offer them, and receives feedback in the form of a list of the types of school where these subjects can be found.

The feedback can be printed, saved, or forwarded via email to a selected recipient. The tool can then be used again with a different choice of five subjects. Subjects not offered in lower secondary schools have text boxes with brief descriptions, something that pupils who tested the tool suggested. The clear connection between input and output can inspire pupils to choose other combinations and may lead to them reconsidering their subject priorities, and discovering other types of upper

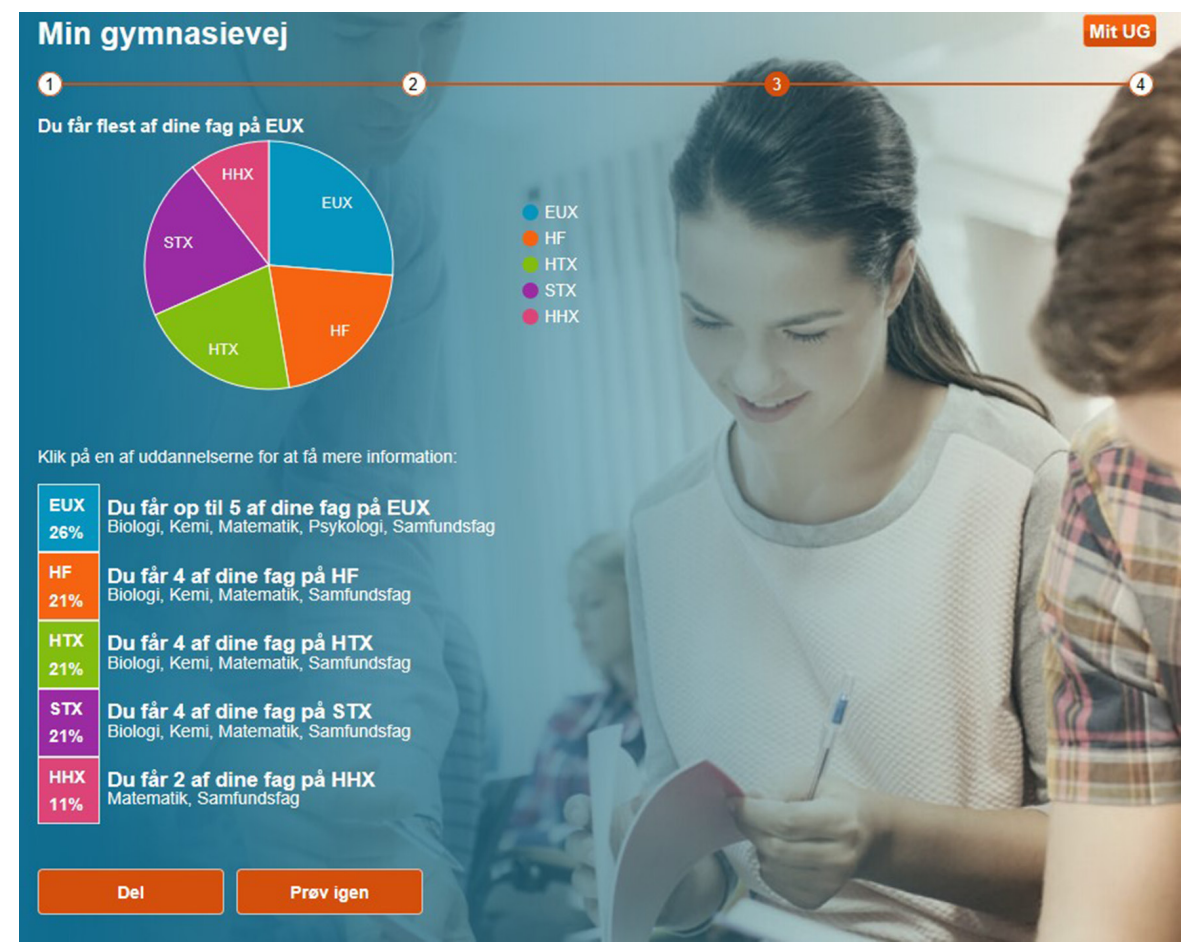

Figure 9.2. The result of a trial run of My Way to Upper secondary (Min Gymnasievej): up to 5 of your subjects at an EUX school, 4 of them at an HF school etc. 
secondary schools. Feedback from practitioners says that My Way to Upper secondary (Min Gymnasievej) supports collective guidance sessions in schools, especially before and after the pupils' obligatory participation in an introductory course at an upper secondary school. This tool has got the highest rating (among Mit $\mathrm{UG}$ - my UG tools) from the pupils and from teachers/practitioners in UG's user survey. The popularity might be related to the reduction of the complexity of options available.

In the second tool, My Strengths (Mine Styrker), the pupil works with reflection by identifying and using personal strengths as they are defined in positive psychology (Seligman, 2003). The primary idea is to focus on well-being and on situations where we feel good and do well. The tool operates with 24 universal positive character traits, that everybody possesses to some extent, where some few are our top strengths. If we utilise them we will find ourselves in the optimal learning situation, be in flow or personal growth. The idea is that focusing on strengths will automatically give energy to tackle things that can be more difficult. These strengths can be used in many different situations, and are thus quite different from specific abilities, competence at school subjects or special talents. The tool has been thoroughly tested in analogue form, cards are selected, prioritised and discussed in small groups in a collective guidance session. My Strengths is a tool intended to spark reflection, and aims at increasing the pupil's self-knowledge by becoming conscious of her strengths and characteristics. Since the tool addresses the complexity of selfperception, and so demands a high level of reflection, it is first and foremost meant as an independent pupil activity, where the counsellor has introduced the concept of strengths first. Practitioners who lead the collective career guidance in schools gave feedback stating that the My Strengths tool is challenging for pupils conceptually and linguistically, and help from a counsellor is called for if benefits are to be won as far as reflection is concerned.

Besides the tools UG provides ideas as to how to make use of the developed tools. For example, there is an inspirational article for practitioners with idea for guidance sessions with focus on strengths. The tool is one of several elements in a session of about two hours. As an introduction to strengths the counsellor can use a ready-made Prezi-presentation, and the speed-sketch film "Find your strengths" (Find dine styrker). The pupils then choose one or more strengths that they feel are characteristic for them. Subsequently the pupils work in groups with cases where four young people are described, and where their strengths are gauged by the group. After this exercise the pupils are introduced to My Strengths via an instructional film, and then work individually with the tool. The pupil has to describe with a single word a situation from their own experience where she was glad and focused. It could be a project, a football match, a favourite subject or something else entirely. Thinking of that situation the pupil now has to say (1) to what extent the personal challenge was at the right level (2) whether she lost her sense of time (3) whether focus could be maintained and (4) whether the situation was under control. It is the motivated and absorbing activity that is the starting point for identifying strengths. If 
the pupil has a high score meaning many 'yes' or 'yes partly' answers, then she has to identify what it was that made her particularly happy in that situation. The pupil has to choose at least one of the 24 strengths categorized in 6 areas of strength: You think things over; You are there for others; You have the courage to be yourself; You have discipline, and The world is bigger than you. After this choice the pupil is given a recap with a text box in which she can describe which strength she will use in the immediate future and how. The result can be printed out, saved or sent forwarded via email to a chosen recipient. Afterwards the group discuss their experiences and reflect on their choices. Finally, in plenum, the young people discuss what insight they have gained about themselves, and how they can continue working along these lines in school, at home with the family and in their leisure time. So technology can help build scaffolding around the pupils' career choices, and to support the counsellor's activities, but there is, too, a need for scaffolding around the actual integration of technology in career guidance activities.

\section{CHALLENGES}

Despite the high level of digitalisation in Denmark, the development and use of digital self-help guidance tools has its challenges. One general challenge in the use of the tools, either as part of collective guidance or independently, is young people's lack of a navigation strategy both on the UG portal and on the internet. Young people are proficient with computers, tablets and smart phones, but they need to be trained on planned search strategy, targeted use of the tools such as UG and a critical appraisal of the results provided by such self-help tools.

The demand for digitalised guidance tools from counsellees, practitioners and politicians will presumably increase as more and more areas of our lives are digitalised. The UG tools have been received generally well and have been evaluated positively in our user surveys. My Way to Upper secondary (Min Gymnasievej) scores 4.1 and My Strengths (Mine Styrker), 3.9 on a scale of 1 to 5. There is however still a great potential if the knowledge and use of these tools were increased amongst both pupils and practitioners (Lagoni, Hein, \& Beigi, 2017).

The pitfall for any digital tool on UG could be that they tend to be built on a generalised content, which can have a negative effect on the learning benefits for the individual, and for usage of the tool. There is always a risk that the simplification of complex problems will be an oversimplification, with a consequent reduction of their significance. Currently no survey exists to show whether that is the case here. In cooperation with school counsellors a number of barriers to the integration of guidance technologies were, in 2017, identified. One of these was the counsellors' expressed need to feel ownership of and motivation for the UG to be used in a counselling course. That means that counsellors often do not adopt the materials and course suggestions in the toolboxes on UG directly. Furthermore, it is known that the counsellors own perception of technology and their prejudices about the limited 
use of digital tools in guidance situations, prevents them from producing their own creative plans with technology integrated in them (e.g. Kettunen, Vuorinen, \& Sampson, 2013; Lagoni et al., 2017).

The development of UG tools is challenged by its financing, for the economic resources are granted piecemeal, and for the most part as part of a political initiative that does not take due consideration of the vision of easy access to life-long guidance. Resources for development are thus given with a specific focus from the topical political agenda, often earmarked for one particular tool at a time - which is another reason why the tools are separate entities that exist independently of each other. The development of each tool has to be approved at each stage by a political committee consisting of representatives of the organisations involved in that particular area of education, who often have high expectations of what the tool will be able to do. However, counsellors know from experience, that digital guidance tools function best when the problems they address are not too complex. Using a digital tool is thus not a quick fix as far as career guidance and counselling is concerned. Nor can career learning technologies be constructed so as to give a pre-determined learning benefit, but they can contribute to giving structure and to indicating a possible path for future plans. Self-help via UG's digital portal has to be seen together with the other guidance activities and options. The tools can be used before, during or after formal guidance as desired, independently or after an introduction by a guidance counsellor. They cannot stand alone, but they are an extension of possibilities for active career learning.

\section{CONCLUDING REMARKS}

The UG is constructed as a guidance resource for those seeking guidance and for counsellors, who provide information on education and employment, tools and films for self-help, and offer digitally based guidance, individually or collectively. Thus UG fulfils its ambition, to be a resource that facilitates finding and choosing an education or an employment, by being at one and the same time an online reference book with relevant information in multimedia format, a channel for synchronous or asynchronous communication with professional guidance counsellors in eVejledning and a resource for self-help via interactive tools.

ICT used in career guidance and counselling is an emerging area worldwide. More research evidence on the actual impact of this use on the counsellee's career learning is needed. And training opportunities for career practitioners in this special field (Kettunen, Lindberg, Nygaard, \& Kardal, Chapter 11, this volume) are increasingly important to support the integration of digital media in the career guidance services in general.

\section{REFERENCES}

Alm, E., Colliander, N., Deforche, F., Lind, F., Stohne, V., \& Sundström, S. (2016). Digitizing Europe: Why Northern European frontrunners must drive digitization of the EU economy. Stockholm, Sweden: Boston Consulting Group. 


\section{A. JOCHUMSEN}

Andersen, J. (2008). Jeg snakker med mig selv ... [Talking to myself ...]. In E. Hansen, D. Kreutzfeldt \& I. Sylvestersen (Eds.), Digitale mellemveerender [Digital matters] (pp. 63-87). Aarhus, Denmark: Philosophia.

Agency for Digitalisation. (n.d). The digital strategy 2016-2020. Copenhagen. Retrieved from https://en.digst.dk/policy-and-strategy/digital-strategy/

Danmarks Statistik. (2017). It-anvendelse i befolkningen [IT usage by Danish households and individuals]. Copenhagen, Denmark: Danmarks Statistik.

European Commission. (2000, October 31). A memorandum on lifelong learning (Commission staff working paper). Brussels: Commission of the European Communities.

European Commission. (2017a). Digital economy and society index. Retrieved from https://ec.europa.eu/ digital-single-market/en/desi,accessed

European Commission. (2017b). Europe's Digital Progress Report (EDPR) 2017, Country profile Denmark. Retrieved from http://ec.europa.eu/newsroom/document.cfm?doc_id=44298

Eurostat. (2018). Digital economy and society statistics - Households and individuals. Luxembourg: Eurostat. Retrieved from https://ec.europa.eu/eurostat/statistics-explained/index.php/Digital_economy_ and_society_statistics_- households_and_individuals\#Internet_access

Hansen, S. S. (2013). Argang 2012 [The class of 2012]. Copenhagen, Denmark: Informations Forlag.

Hansen, S. S. (2015). Digitale indfødte på job [Digital natives going to work]. Copenhagen, Denmark: Gyldendal Business.

Hansen, T. I. (2012). Evaluering af digitale loeremidler [A framework for evaluating E-learning tools]. Odense, Denmark: læremiddel.dk.

Hansen, T. I., \& Bundsgaard, J. (2013). Kvaliteter ved digitale laeremidler og ved paedagogiske praksisser med digitale laremidler [The advantages of E-learning tools and the pedagogical approaches to E-learning]. Forskningsrapport, Creative Commons.

Kettunen, J., Vuorinen, R., \& Sampson Jr., J. P. (2013). Career practitioners' conceptions of social media in career services. British Journal of Guidance \& Counselling, 41, 302-317. doi:10.1080/ 03069885.2013.78157

Kettunen, J., Vuorinen, R., \& Sampson Jr., J. P. (2015). Practitioner's experience of social media in career services. The Career Development Quarterly, 63, 268-282. doi:10.1002/cdq.1218

Knapp, J., Zeratsky, J., \& Kowitz, B. (2016). Sprint. How to solve big problems and test new ideas in just five days. New York, NY: Simon \& Schuster.

Lagoni, L., Hein, K., \& Beigi, M. (2017). Kortlcegning. Praksis i den kollektive vejledning og brug af digital vejledning [Overview. Practice in collective career guidance and the usage of digital career guidance and online tools]. UU-Danmark and Undervisningsministeriet, Styrelsen for it og læring.

Law, B. (2001). New DOTS: Career learning for the contemporary world. NICEC.

Law, B. (2010). Career learning in the net. Colonise or inhabit. Retrieved from http://www.hihohiho.com

Plant, P. (2006). Five swans in 3-D: Nordic educational and vocational guidance. International Association for Educational and Vocational Guidance Newsletter, 55, 1-4.

Plant, P. (2009). Vejledning mellem tilbud og tvang [Between choice and coercion]. Vejlederforum, 2. Valby, Denmark: Schultz Information.

Reimer-Mattesen, T. (2012). SAMR - hvad bruger vi egentlig teknologien til? [SAMR - Why do we use technology?]. Retrieved from http://laeringsteknologi.dk

Rogers, C. (1951). Client-centered therapy. Boston, MA: Houghton Mifflin Company.

Sampson, J. P., Lenz, J. G., Reardon, R. C., \& Peterson, G. W. (2003). Key elements of the CIP approach to designing career services (Unpublished manuscript). Florida State University, Center for the Study of Technology in Counseling and Career Development, Tallahassee.

Seligman, M. (2003). Authentic happiness. using the new positive psychology to realize your potential for lasting fulfilment. London: Nicholas Brealey Publishing. 